Thélème. Revista Complutense de Estudios Franceses

ISSN-e: 1989-8193

http://dx.doi.org/10.5209/THEL.55062

\title{
Inserción del concepto de mito en las descripciones del invernadero del hôtel Saccard en La Curée de Émile Zola
}

\author{
María Custodia Sánchez Luque ${ }^{1}$
}

Recibido: 26 de enero de 2017 / Aceptado: 27 de marzo de 2017

Resumen. En este ensayo abordamos una temática recurrente en aquellos textos de Zola en los que el jardín desempeña un papel primordial: la inserción del concepto de mito. Con este propósito efectuamos un análisis minucioso del discurso poético de las dos descripciones del invernadero del palacete Saccard en La Curée, que nos ayudará a desvelar una dimensión profunda del pensamiento zoliano: su búsqueda de elementos mitológicos y simbólicos camuflados en el jardín, lugar de comunicación ideal con la naturaleza. Dicha búsqueda nos invita a una reflexión sobre los efectos de la civilización científico-técnica, centrada en la razón, que no por ello es capaz de eliminar la necesidad de lo oculto y lo fantástico.

Palabras clave: Zola; mito; naturaleza; jardín.

[fr] L'inclusion de la notion de mythe dans les descriptions de la serre de l'hôtel Saccard dans La Curée d'Émile Zola

Résumé . Dans cet essai, nous traitons un sujet récurrent dans les textes de Zola où le jardin joue un rôle majeur: l'inclusion de la notion de mythe. À cet effet, nous avons réalisé une analyse approfondie du discours poétique des deux descriptions de la serre de l'hôtel Saccard dans La Curée, qui nous aidera à révéler une dimension profonde de la pensée zolienne: sa quête d'éléments mythologiques et symboliques camouflés dans le jardin, cet endroit de communication idéale avec la nature. Cette quête nous invite à réfléchir sur les effets de la civilisation scientifique et technologique, centrée sur la raison, qui n'est pas, pour autant, capable d'éliminer la recherche de l'occulte et du fantastique.

Mots clés : Zola; mythe; nature; jardin.

[en] The Insertion of the Concept of Myth in the Descriptions of the Greenhouse of Hôtel Saccard in La Curée, by Émile Zola

\begin{abstract}
In this essay we broach a recurring issue in those Zola novels in which the garden plays a primordial role: the insertion of the concept of myth. To this purpose we aim to carefully analyze the poetic discourse in the two descriptions of the greenhouse of hôtel Saccard in La Curée, with a view to unveil a deep dimension of Zola's thinking: his search for mythological and symbolic elements camouflaged in the garden - a place of ideal communication with nature. This search invites us to a reflection on the effects of the scientific and technical civilization, centered on reason, but unable to eliminate the quest for the occult and the fantastic.
\end{abstract}

Key words: Zola; myth; nature; garden.

Universidad Complutense de Madrid

mariac32@ucm.es 
Sumario: 0. Introducción. 1. Zola evocador de mitos. 2. El simbolismo de la luna. 3. Mitología bíblica, 4. Referencias bibliográficas.

Referencia normalizada: Sánchez Luque, M. C. (2017). «Inserción del concepto de mito en las descripciones del invernadero del hôtel Saccard en La Curée de Émile Zola». Thélème. Revista Complutense de Estudios Franceses, Vol. 32, Núm. 2: 301-313.

\section{Introducción}

El propósito de este artículo es desvelar las referencias al mito subyacentes en las descripciones del invernadero del hôtel Saccard de La Curée ${ }^{2}$ de Émile Zola. Para ello nos centraremos en el análisis detallado del discurso poético en las dos grandes presentaciones que se hacen de este jardín, en los capítulos I y IV respectivamente que aparecen desde el punto de vista narrativo como digresiones-. Al ser el invernadero símbolo de toda la novela, y al reflejar la red metafórica de sus descripciones toda la temática de la obra, su estudio nos ha remitido necesariamente a otros pasajes del relato, dado que las descripciones del invernadero resumen las imágenes que se dispersan por toda la novela.

Como escriben Van Buuren y Firet en su artículo Splendeur et misère: le Paris du Second Empire vu par Émile Zola, en el interior de la imagen de París, Zola sitúa una imagen en miniatura que resume las tendencias del conjunto: esta es la del invernadero adosado al palacete Saccard (Van Buuren/ Firet, 1997: 131). Entendemos que las presentaciones de este jardín cerrado son una puesta en abismo de La Curée - procedimiento consistente en la imbricación de un relato dentro de otro-, pues constituyen un reflejo del conjunto del relato y erigen este lugar en emblema de toda la novela.

\section{Zola evocador de mitos}

Al analizar el sistema metafórico en Zola, coincidimos con Etienne Rabaté en su idea de que leer a este autor es reconocer la profusión de la creación metafórica; así, la crítica presenta con frecuencia a un escritor dividido: positivista en el proyecto y visionario en la escritura, creador de mitos cuya coherencia se opone a las convicciones expuestas por el realismo y la ciencia (Rabaté, 1989: 112).

Zola, que ejerció como crítico de arte durante 30 años, tuvo que debatirse, según apunta Ingeborg Waldinger en Zola et la peinture, entre dos sentimientos contrarios: su inclinación hacia la perfección científica, así como hacia una expresión realista de la vida contemporánea, por un lado, y su deseo de trascender ese orden de realidades determinadas, en pos de una visión simbolista y mítica del universo, por otro (Ingeborg, 1990: 1).

Todas las citas que hagamos de esta novela, estarán tomadas de la edición de 1970 de GF Flammarion, con prólogo de Claude Duchet. 


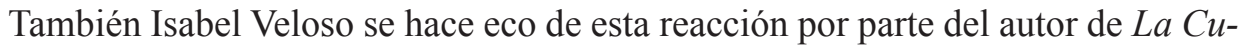
rée ante el racionalismo, el positivismo y el ciencismo del siglo XIX, cuando afirma lo siguiente:

Zola, que se quiso adalid del realismo científico, vio cómo su temperamento natural y su herencia romántica provocaban irremediablemente una serie de derivas que, por suerte, transgredieron los límites del realismo más teórico para alimentarse del sustrato mítico general y procesarlo en el texto en forma de mitología personal (Veloso, 2004: 228).

Pierina Lidia Moreau parafrasea a Henri Mitterand, en su obra Zola et le Naturalisme, cuando este recuerda la frecuencia con la que el novelista recurre a los mitos para estructurar sus novelas; así, Mitterand señala el mito del eterno retorno en $L a$ Terre, los mitos de fundación en La Fortune des Rougon, Fedra en La Curée, y los mitos del paraíso perdido y de Cibeles (encarnado por el personaje de Désirée) en La Faute de l'abbé Mouret, entre otros (Mitterand, 2002, citado por Moreau, 1995: 180).

Jeon Hye-Jeong pone de relieve la conocida voluntad documental y científica de Zola. El objetivo del naturalismo es, por principio, construir una literatura sin mitos ni tabúes; las actitudes naturalistas se caracterizan por la certeza de que no existen fuerzas misteriosas que no se puedan aclarar y nombrar, es decir, dominar. Sin embargo, los críticos zolianos no dejan de constatar que los mitos desempeñan un papel considerable en su obra. La tesis de Roger Ripoll Réalité et Mythe chez Zola, se centra en el Zola creador de mitos. En la línea de la psicocrítica de Charles Mauron, que define el mito en términos del inconsciente del autor, Roger Ripoll muestra la formación de mitologías personales con respecto a la realidad (Hye-Jeong, 1994: 6-10).

El tema del jardín nos remite, como apunta María Cóndor, a uno de los mitos más primordiales del ser humano, el anhelo de una vida feliz en armonía con la naturaleza, de la que se supone que antaño este formó parte y de la que se separó en algún momento difícil de precisar (acaso la Grecia helenística); debatiéndose entre un estado natural y las exigencias de la vida social y urbana, "Pero sin duda hizo falta esta separación para que el hombre iniciara la consideración estética y emocional de la naturaleza — antes solo el marco de sus trabajos por sobrevivir-, igual que el hijo no aprende a amar a la madre hasta que deja de formar parte de ella" (Cóndor, 2013: 28).

Asimismo, Chiwaki Shinoda, al reflexionar sobre las razones que han podido influir en el interés por la exuberancia vegetal de ciertos literatos franceses en el último tercio del siglo XIX, entre los que se encuentra Zola, apunta a circunstancias como el peligro de desaparición por el que pasaba el bosque francés en la época, como consecuencia de la vorágine urbanística. El propio Zola se lamenta en su texto sobre los bosques "Hélas! On coupe en ce moment ma chère fôret! [...] Toute la forêt, navrée, devenue lugubre, pleurait" (Zola, cita de Shinoda, 2001: 59). Los bosques se talaban para construir barcos de guerra con los troncos de los árboles, y para aprovechar las ramas para la calefacción; en todos los bosques se construían fundiciones y hornos de vidrio; se expulsaba a los rebaños, etc. Estos escritores no se lamentan solamente por la desaparición del bosque francés, sino también por la de otros: "Partout les arbres sont abattus, le paradis terrestre de l'Asie ou du Pacifique est menacé de l'anéantissement dû à l'exploitation impérialiste" (Shinoda, Ibidem). 
El sentimiento de reacción contra el estado de los bosques que se desprende de lo arriba indicado, nos pone en contacto con mitos como los del paraíso perdido o el del bosque encantado. No es de extrañar, por lo tanto, que Zola enalteciera bosques utópicos que no existían realmente, tal es el caso del Paradou en La Faute de l'abbé Mouret, definible como un espacio hiperbólico y misterioso:

C'est la forêt imaginaire, le château de la Belle au bois dormant. C'est en réalité un jardin abandonné. Mais, sous la plume de Zola, il prend une ampleur démésurée, presque mythique. C'est la forêt habitée par des esprits sylvestres. [...] Les arbres ont des voix pour encourager les jeunes gens à l'amour [...], ce jardin redevenu sauvage redevient mythique, animé de la vie des dieux et des fées, qui guident Albine et Serge dans la voie de la connaissance sexuelle (Shinoda, 2001: 60).

Ya hemos señalado la frecuencia con la que Zola invoca los mitos para constituir sus novelas. Pero, ¿Por qué vincular directamente la inserción del concepto de mito con el tratamiento del jardín en Zola? El propio autor, en su ensayo De la description, perteneciente a su obra Le Roman experimental, proporciona la respuesta a esta pregunta, cuando afirma que "La nature est entrée dans nos oeuvres d'un élan si impétueux, qu'elle les a emplies, noyant parfois l'humanité" (Zola, 1880: 229), dando a entender con ello que la naturaleza le parece tan poderosa, tan grandiosa y absoluta, que resulta difícil implicarse en ella sin entregarse por completo y perder la cabeza, sin construir mitos, sin dejar de existir en el mundo de todos los días para penetrar en un mundo transfigurado, lleno de seres capaces de realizar acciones de tipo sobrenatural (Sánchez Luque, 2016: 205). Tras elogiar el tratamiento de la descripción en los Goncourt y, sobre todo, en Gustave Flaubert, Zola nos habla de sí mismo:

Nous avons été moins sages, moins équilibrés. La passion de la nature nous a emportés, et nous avons donné de mauvais exemples, par notre exubérance, par nos griseries du grand air. [...] On rêve alors toutes sortes de choses folles, on écrit des oeuvres où les ruisseaux se mettent à chanter, où les chênes causent entre eux, où les roches blanches soupirent comme des poitrines de femme à la chaleur du midi (Zola, 1880: 232-232).

Solamente la naturaleza puede inspirar "[les] amours des Palmiers et des Fougères" (La Curée: 202), "feuillages [qui] prenaient des apparences confuses et équivoques, que leurs désirs fixaient en images sensuelles" (Ibídem.), "des murmures, des chuchotements [qui] venaient des massifs, voix pâmées, soupirs d'extase, cris étouffés de douleur, rires lointains" (Ibídem.), y una flor de vainilla "[qui] chantait avec de roucoulements de ramier" (Ibídem.).

Según Pierre Albouy, para que el mito literario exista hace falta que la obra contenga referencias más o menos explícitas a un mito tradicional, del que el texto reproduce las estructuras y la significación. Además, el texto debe presentarse como una palingénesis del mito, es decir, añadiéndole significados nuevos (Albouy, 1970: 1062, citado por Moreau, opus cit.: 193). En La Curée se cumplen con creces estas condiciones.

Esta explicación de Albouy es relacionable con la exposición de Javier del Prado al respecto de la inserción del concepto de mito en la obra literaria. En su artículo Du mythe à L'archéologie mythique, Javier del Prado plantea la pregunta de por qué 
"arqueología mítica" y no simplemente "mito". A lo que responde que la arqueología mítica nos sitúa frente a elementos que han llegado hasta nosotros fragmentados en pedazos, que han perdido la función para la que habían sido creados y los lazos que los unían para formar un conjunto. Traduciendo esto a términos literarios, se trata de defender la organización sintagmática (es decir, temporal y actualizada) del texto, frente a las estructuras paradigmáticas atemporales, con valor universal de mito. La noción de mitologema empleada por Durand plantea la razón de ser de un mito, pero también el motivo de la posible desaparición de ese mito, cuando un mitologema ha dejado de tener sentido. Un mito tiene razón de ser dentro de los sistemas en los que este ha nacido; fuera de esos sistemas plantea problemas que hay que resolver para que pueda ser integrado en los nuevos sistemas, mediante lo que Javier del Prado llama, por influencia de Lévi-Strauss, el "bricolaje conceptual y simbólico". Hay que sacar la noción de mitologema de su sacralidad, para entender que ciertos mitologemas han desaparecido o pueden desaparecer, a medida que se producen nuevas situaciones en la Historia. Se trata de pasar de una visión esencialista, preexistente a la temporalidad de los problemas tratados en los textos, a una visión existencialista. Esto solo es posible si dejamos que cada elemento imaginario encuentre su lugar libremente, dentro de una nueva cosmovisión. Para Lévi-Strauss los mitos no tienen un valor intrínseco, sino que dependen del lugar donde se encuentren en una estructura. Su valor, por lo tanto, no es esencial, sino conceptual (Prado Biezma, 1995: 137-137).

Siguiendo a Javier del Prado, la conclusión certera en el caso de La Curée - y es aquí donde se inserta a nuestro entender el concepto de mito adaptado al tiempo de la obra literaria - sería que esta exuberancia vegetal, este jardín hiperbólico y quimérico simboliza la decadencia de la sociedad francesa de finales del siglo XIX. Esta confusión de la sociedad parisina es metaforizada por la confusión del invernadero. La ausencia de barreras arquitectónicas con el exterior del invernadero también es metafórica de la ausencia de barreras morales y de reglas de todo tipo. La sociedad que pinta Zola es una sociedad enferma, carente de autoridad y reglas éticas. En el invernadero también encontramos elementos portadores de ese significado, que traen a la mente la idea de enfermedad y deformidad, como los "Euphorbes d'Abyssinie [...] contrefaits, plein de bosses honteuses" (La Curée: 73), las "plantes bizarres [...] avec un éclat sombre ou pâlissant de fleurs malsaines" (Ibídem), las "Orchidées [...] qui poussent de toutes parts leurs rejets trapus, noueux et déjetés comme des membres infirmes" (La Curée: 74), o los "Euryales [avec] leurs feuilles lepreuses, nageant à plat comme des dos de crapauds monstrueux couverts de pustules" ( $L a$ Curée: 72-73).

Se trata de un mundo sin fundamentos, en el que todo es artificial: Napoleón III ha robado su trono, Saccard construye su palacete sobre un terreno robado a la villa de París. Igualmente, de las plantas del invernadero, que han sido arrancadas de su hábitat natural, se podría decir que son seres desarraigados, de vida artificial, puesto que dependen totalmente del invernadero para sobrevivir, ya que no podrían hacerlo en el clima exterior de París. 


\section{El simbolismo de la luna}

Un tema a destacar en este análisis de la inserción del concepto de mito, es el cometido de la luna en las escenas acontecidas en el invernadero. No es de extrañar que la luna, al contemplar la escena de amor entre Renée y Maxime, descrita al final del capítulo IV, "animait le drame de sa lumière changeante" (La Curée: 203), dada su relación con el poder femenino, con la fertilidad y con lo telúrico. Pese a la escasa concentración metafórica de la figura de la luna en la segunda descripción del invernadero, creemos, sin embargo, que su desarrollo paradigmático es importante, no solo porque el simbolismo lunar integra en un único sistema realidades tan diversas como la mujer, las aguas, la vegetación, la serpiente, la fecundidad y la muerte, todas ellas presentes de forma más o menos directa en este jardín, sino también por el hecho de que sea la noche el momento elegido para las dos grandes escenas que se desarrollan en el invernadero (Sánchez Luque, opus cit.: 208). Como sostiene Mircea Eliade en su Tratado de Historia de las religiones, desde los tiempos más remotos, desde el neolítico por lo menos, aparece en el momento en que se descubre la agricultura, un simbolismo que vincula entre sí a la luna, las aguas, la lluvia, la fecundidad de la mujer y la de los animales, la vegetación, el destino del hombre después de la muerte y las ceremonias de iniciación. El descubrimiento del ritmo lunar hizo posible esas síntesis mentales que ponen en relación y unifican realidades heterogéneas (Eliade, 1964: 189).

En efecto, llama la atención que sea siempre la magia de la noche la que haga aflorar en Renée deseos inconfesables; es la noche la que hace que el mismo bosque, el de Boulogne, mundano durante el día, sea sagrado cuando oscurece, la ocasión que aprovechaban los dioses antiguos para esconder sus adulterios y sus incestos. Cuando la acción de la novela comienza, todavía por la tarde, Renée, que está asistiendo, junto con su hijastro Maxime, a un paseo en calesa por el parque de Boulogne, manifiesta sentir un profundo aburrimiento: “Oh! je m'ennuie, je m'ennouie à mourir" (La Curée: 44). Sin embargo, a medida que la noche cae, el interés de la joven se anima:

Renée, dans se satiétés, éprouva une singulière sensation de désirs inavouables, à voir ce paysage qu'elle ne reconnaissait plus, cette nature si artistement mondaine, et dont la grande nuit frissonnante faisait un bois sacré, une de ces clairières idéales au fond desquelles les anciens dieux cachaient leurs amours géantes, leurs adultères et leurs incestes divins (La Curée: 46).

El bosque de Boulogne, que durante el día es un lugar atestado de elegancia, se va convirtiendo poco a poco, a medida que anochece, en una suerte de bosque sagrado, un lugar mítico. La alusión a los amores de los dioses y las diosas de la mitología sirve para transcribir los deseos secretos de Renée, sus ensoñaciones.

En relación con lo arriba citado, encontramos un vínculo entre estas tres escenas: 


\begin{tabular}{|c|c|c|}
\hline $\begin{array}{l}\text { 1) PARQUE MONCEAU } \\
\text { CONTEMPLADO DES- } \\
\text { DE LA VENTANA DE LA } \\
\text { HABITACIÓN DE RE- } \\
\text { NÉE. CAPÍTULO I }\end{array}$ & $\begin{array}{l}\text { 2) ALUSIONES AL BOIS } \\
\text { DE BOULOGNE Y AL } \\
\text { PARQUE MONCEAU, } \\
\text { CUANDO RENÉE ESTÁ } \\
\text { EN EL INVERNADERO. } \\
\text { CAPÍTULO I }\end{array}$ & $\begin{array}{l}\text { 3) EL PARQUE MON- } \\
\text { CEAU REFERIDO TRAS } \\
\text { LA ESCENA CON MAXI- } \\
\text { ME Y SACCARD EN EL } \\
\text { TOCADOR DE RENÉE. } \\
\text { CAPÍTULO VI }\end{array}$ \\
\hline $\begin{array}{l}\text { Alors, elle se mit à rêver, } \\
\text { avec une joie puérile, aux } \\
\text { belles parties de raquette } \\
\text { qu'elle avait faites jadis } \\
\text { avec sa jeune soeur Chris- } \\
\text { tine. Et, quelque matin, } \\
\text { elle s'éveillerait du rêve de } \\
\text { jouissance qu'elle faisait } \\
\text { depuis dix ans, folle, salie } \\
\text { par une des spéculations de } \\
\text { son mari [...]. Ce fut comme } \\
\text { un presentiment rapide. Les } \\
\text { arbres se lamentaient à voix } \\
\text { plus haute. Renée, troublée } \\
\text { par ces pensées de honte et } \\
\text { de châtiment, céda aux ins- } \\
\text { tincts de vieille et honnête } \\
\text { bourgeoisie qui dormaient } \\
\text { au fond d'elle; elle promit à } \\
\text { la nuit noire de s'amender, } \\
\text { de ne plus tant dépenser } \\
\text { pour sa toilette, de chercher } \\
\text { quelque jeu innocent qui } \\
\text { pût la distraire, comme aux } \\
\text { jours heureux du pension- } \\
\text { nat (La Curée: } 54 \text { ). }\end{array}$ & $\begin{array}{l}\text { Et, sous la lumière vive, Re- } \\
\text { née songeait, en regardant } \\
\text { de loin Louise et Maxime. } \\
\text { Ce n'était plus la rêverie } \\
\text { flottante, la grise tentation } \\
\text { du crépuscule, dans les al- } \\
\text { lées fraîches du Bois. Ses } \\
\text { pensées n'étaient plus ber- } \\
\text { cées et endormies par le trot } \\
\text { des chevaux, le long des } \\
\text { gazons mondains, des taillis } \\
\text { où les familles bourgeoises } \\
\text { dînent le dimanche. Main- } \\
\text { tenant un désir net, aigu, } \\
\text { l'emplissait (La Curée: 75). } \\
\text { À cette heure de vision } \\
\text { nette, toutes ses bonnes ré- } \\
\text { solutions s'évanouissaient } \\
\text { à jamais, l'ivresse du dîner } \\
\text { remontait à sa tête, impé- } \\
\text { rieuse, victorieuse, dou- } \\
\text { blée par les flammes de } \\
\text { la serre. Elle ne songeait } \\
\text { plus aux fraîcheurs de la } \\
\text { nuit qui l'avaient calmée, } \\
\text { à ces ombres murmurantes } \\
\text { du parc, dont les voix lui } \\
\text { avaient conseillé la paix } \\
\text { heureuse (La Curée: } 76 \text { ). }\end{array}$ & $\begin{array}{l}\text { Et elle se dit qu'une seule } \\
\text { fois elle avait lu l'avenir, le } \\
\text { jour où, devant les ombres } \\
\text { murmurantes du parc Mon- } \\
\text { ceau, la pensée que son } \\
\text { mari la salirait et la jetterait } \\
\text { un jour à la folie, était ve- } \\
\text { nue effrayer ses désirs gran- } \\
\text { dissants. [...] Elle pleurait } \\
\text { de ne pas avoir écouté les } \\
\text { grandes voix des arbres (La } \\
\text { Curée: } 289) \text {. }\end{array}$ \\
\hline
\end{tabular}

En el fragmento de la columna 1 del cuadro, Renée, ya preparada para la cena de gala que se va a celebrar esa noche en su casa, se detiene unos minutos a contemplar el parque Monceau desde la ventana de su habitación, mientras que hace un breve balance de su vida pasada y tiene una premonición. En ese momento la mujer alberga pensamientos positivos así como propósitos de enmienda, todo lo cual encuentra buen caldo de cultivo al venir inspirado por el parque Monceau. Estos sentimientos se oponen a los que afloran en su interior cuando, más tarde esa misma noche, en las dos escenas extractadas en la columna 2, Renée se encuentra inmersa en el ambiente viciado del invernadero, donde siente renacer sus sentidos de mujer ardiente:

Ce fut pendant cette promenade d'automne, au crépuscule, quand le Bois s'endormait, que l'idée vague de l'inceste lui vint [...], cette idée se précisa, se dressa 
ardemment devant elle, au milieu des flammes de la serre, en face de Maxime et Luise (La Curée: 197-198).

En el fragmento de la tercera columna, del final del capítulo VI, Renée, vejada por Saccard y Maxime, siente que su premonición se ha cumplido. Hay un hilo conductor entre la premonición de Renée, evocada en la cita de la columna 1, según la cual ella se despertaría un día de su ensueño de felicidad para encontrarse ultrajada a causa de una especulación de su marido, y la materialización de esta premonición en la cita de la columna 3. Por otro lado, si, como se insinúa en la cita de la columna 1 y se pone de manifiesto en la de la 3 , Renée no es para Saccard más que un objeto, un medio útil para la consecución de sus fines, es muy importante para la mujer el poder ser ella misma en algún lugar. Ese lugar es el invernadero, en el que se evidencia su verdadera personalidad, como queda reflejado en las citas de la columna 2.

Asimismo, los tres bloques de citas quedan unidos por las personificaciones de los árboles, los cuales parecen querer proteger a la heroína. Estas personificaciones intensifican la expresividad de las descripciones aumentando así nuestra empatía y reacción emocional ante el drama que se adivina: en la primera cita "Les arbres se lamentaient a voix plus haute" cuando intuían que Renée sería vejada un día por Saccard; en la segunda "[Renée] ne songeait plus [...] à ces ombres murmurantes du parc, dont les voix lui avaient conseillé la paix heureuse", desoyendo así los consejos de sus "amigos", mientras que en la tercera es Renée la que se lamenta por no haber prestado atención a las recomendaciones de éstos, cuando ya es demasiado tarde: "Elle pleurait de ne pas avoir écouté les grandes voix des arbres".

Otro de los aspectos de la mitología lunar que nos interesa es su relación con la muerte. En efecto, siguiendo a Eliade, la luna es el primer muerto. Durante tres noches la luna desaparece del cielo, pero al cuarto día renace y, como ella, los muertos adquirirán un nuevo modo de existencia. La muerte no es una extinción sino una modificación del plano vital. En este sentido, la participación de la luna en la escena que transcurre en el invernadero puede ser también anuncio de la muerte y regeneración de Renée; pero, si bien esta fallece al final de la novela, vemos cómo en la escena inmediatamente anterior a la mención de su muerte, la joven acude a refugiarse a su antigua habitación infantil del hôtel Béraud, desde donde se divisa el Sena, símbolo de la madre, fuente de vida y de regeneración. Esta es la razón por la que muchas divinidades lunares son a la vez ctónicas y funerarias, como Perséfone. La concepción de la luna como morada de las almas de los muertos aparece formulada iconográficamente en la glíptica asirio-babilonia, fenicia, hitita y anatolia, y se transmite luego a los monumentos funerarios de todo el Imperio Romano. El símbolo funerario de la media luna es corriente en toda Europa (Eliade, opus cit: 206-208).

\section{Mitología bíblica}

Otro asunto reseñable de la inclusión del concepto de mito en las descripciones del invernadero de La Curée, es el de las alusiones al libro del Génesis. Como indica Clélia Anfray en su libro Zola biblique: La Bible dans les Rougon-Macquart, en toda la obra zoliana abundan las referencias a figuras de la Biblia - Adán y Eva, el rey David y Abigail, la serpiente, etc. - y a sus ciudades —-Sodoma, Babilonia o Nínive- De este libro, Zola extrae buena parte de sus imágenes y motivos. Sabemos 
que utilizaba la traducción que, a partir de la Vulgata, realizaron Jean-Jacques Bourassé y Pierre-Désiré Janvier, ilustrada por Gustave Doré, conocida como la Gran Biblia de Tours, editada en 1866 (Anfray, 2010: 19).

Hay un paralelismo entre las ciudades bíblicas de Sodoma y Gomorra, destruidas, según el Génesis, como castigo por la perversidad de sus habitantes, y el París de la época de Napoleón III, al que Zola, republicano convencido, no puede evitar enjuiciar:

\begin{tabular}{|c|c|}
\hline PARÍS DEL II IMPERIO & SODOMA Y GOMORRA \\
\hline $\begin{array}{l}\text { "L'Empire allait faire de Paris le mauvais } \\
\text { lieu de l'Europe. [...] Et, dans la ville où le } \\
\text { sang de décembre était à peine lavé, gran- } \\
\text { dissait timide encore, cette folie de jouis- } \\
\text { sance qui devait jeter la patrie au cabanon } \\
\text { des nations pourries et déshonorées." (La } \\
\text { Curée: } 85 \text { ). } \\
\text { «C'était l'heure où la curée ardente emplit } \\
\text { un coin de forêt de l'aboiement des chiens, } \\
\text { du claquement des fouets, du flamboiement } \\
\text { de torches. Les appétits lâchés se conten- } \\
\text { taient enfin, dans l'impudence du triomphe } \\
\text { [...]. La ville n'était plus qu'une grande dé- } \\
\text { bauche de millions et de femmes. Le vice, } \\
\text { venu de haut, coulait dans les ruisseaux, } \\
\text { s'étalait dans les bassins, remontait dans } \\
\text { les jets d'eau des jardins, pour retomber } \\
\text { sur les toits en pluie fine et pénétrante. [...] } \\
\text { on sentait le détraquement cérébral, le cau- } \\
\text { chemar doré et voluptueux d'une ville folle } \\
\text { de son or et de sa chair. Jusqu'à minuit, les } \\
\text { violons chantaient; puis les fenêtres s'étei- } \\
\text { gnaient, et les ombres descendaient sur la } \\
\text { ville. C'était comme une alcôve colossale } \\
\text { où l'on aurait soufflé la dernière bougie» } \\
\text { (La Curée: } 151 \text { ). }\end{array}$ & $\begin{array}{l}\text { "Entonces Jehová hizo llover sobre Sodo- } \\
\text { ma y sobre Gomorra azufre y fuego de par- } \\
\text { te de Jehová desde los cielos; y destruyó las } \\
\text { ciudades, y toda aquella llanura, con todos } \\
\text { los moradores de aquellas ciudades, y el } \\
\text { fruto de la tierra" (Génesis 19: 24-25). } \\
\text { "Y miró hacia Sodoma y Gomorra, y hacia } \\
\text { toda la tierra de aquella llanura miró; y he } \\
\text { aquí que el humo subía de la tierra como el } \\
\text { humo de un horno" (Génesis 19:28). }\end{array}$ \\
\hline
\end{tabular}

Como muestran Becker y Lavielle, en su trabajo sobre La Curée, a través de un vocabulario depreciativo de imágenes fuertes, el novelista impone la visión de una Francia que es albergue de todas las promiscuidades y todas las vergüenzas. Esta intención moralizante aparece ya en el título de la obra, que Zola toma prestado de un poema de Iambes et Poèmes, de Auguste Barbier (1831). Al final de una caza de montería, se lanzan las vísceras de los animales cazados a los perros, que se precipitan sobre la comida y se la disputan al estar hambrientos, puesto que no se les ha alimentado para que persigan mejor a la presa. Como los animales, Saccard y sus amigos se disputan la ciudad de París para cebarse de riqueza (Becker \& Lavielle, 1999: 60-61). Este París violento, rapaz, terrorífico, que pinta Zola, es metaforizado por la naturaleza monstruosa del invernadero. 
Si la inserción del asunto bíblico en los Rougon-Macquart va asociada a la idea del pecado original, el tema del jardín ocupa un papel preeminente en este análisis, ya que si hay un espacio en la obra zoliana asociado a la sexualidad y a la idea de pecado, ese es el jardín. Clélia Anfray resalta la concepción pesimista de la religión en los Rougon-Macquart. Si, por un lado, Zola se ha desembarazado de los dogmas del cristianismo, y siente rechazo por una iglesia reacia a la emancipación del hombre así como por el fanatismo del clero, también, por otro, se muestra profundamente impregnado de la noción de culpabilidad y de pecado original. Además, la inserción del concepto de mito en los Rougon-Macquart, según Hans Blumenberg, tiene por finalidad desmontar los terrores y las angustias del hombre mediante su estilización: "maîtriser imaginairement la nature et de mettre à distance la terreur" (Monod, 2008, citado por Anfray, opus cit: 30-32).

Por otro lado, además de asociar el tema bíblico al del jardín, Zola se interesa por la Biblia sobre todo desde el punto de vista de su valor estético, al ser esta una fuente inagotable de imágenes, lo cual enlaza con el carácter pictórico que tiene en general la obra zoliana. Así, no es de extrañar que el autor se apasione con las representaciones de escenas bíblicas de Gustave Doré y de Gustave Moreau.

Algunos motivos que se encuadran en el mito del Génesis, evocados por Zola en las descripciones del invernadero, son la serpiente, el árbol y la manzana.

En lo que se refiere a la serpiente, es significativo que este motivo solo aparezca mencionado en la primera descripción del final del capítulo I, cuando Renée siente nacer en ella la tentación, y que esté ya ausente por completo en la segunda descripción del capítulo IV, cuando la relación entre Renée y su hijastro Maxime es ya un hecho consumado. Al igual que en los textos sagrados, la serpiente aparece aquí como el terrible tentador responsable del pecado:

Leurs bois secs, dénudés, tordus comme des serpents, semblables à de filets de pêcheur pendus au grand air (La Curée: 72).

Les Quisqualus, dont les fleurs pendaient comme des colliers de verroterie, filaient, se coulaient, se nouaient, ainsi que des couleuvres minces, jouant et s'allongeant sans fin dans le noir des verdures (La Curée: 74).

Puis, tout autour, du noir s'entassât; les berceaux, avec leurs draperies de lianes, se noyaient dans les ténèbres, ainsi que des nids de reptiles endormis (La Curée: 75).

Asimismo, consideramos válida para el caso de La Curée, la teoría formulada por Clélia Anfray con respecto al Paradou de La Faute de l'abbé Mouret, según la cual el papel de la serpiente, lejos de estar personificado, está simbolizado por el conjunto del jardín:

C'est le jardin qui, par sa luxuriance et sa débauche de végétations, pousse les deux amants à la faute. Les voix des fleurs, le murmure des arbres, le chuchotement des roses, tout invite les amants à s'unir. [...] Le Jardin participe donc à part entière à l'union des amants et semble même en avoir toute la responsabilité [...]. Les deux jeunes gens succombent alors malgré eux à la tentation, séduits par le murmure du jardin devenu satanique. Car les plantes portent la trace de l'antique Serpent (Anfray, 2005: 51). 
No olvidemos que La Curée fue escrita mucho antes que La Faute de l'abbé Mouret, y que muchos de los temas planteados en la primera van a ser desarrollados generosamente en la segunda. En el caso de las dos obras, Zola evita la presencia manifiesta del diablo (encarnado por la serpiente como tal), y hace cargar a la naturaleza con toda la responsabilidad del pecado.

Los motivos del árbol y de la mordedura de la manzana están relacionados entre sí. El equivalente de este último va a ser en La Curée la mordedura de la hoja de tanguina, que simboliza la realización del pecado original del que todo el invernadero será cómplice:

L'arbuste derrière lequel elle se cachait à demi, était une plante maudite, un Tanghin de Madagascar, aux larges feuilles de buis, aux tiges blanchâtres, dont les moindres nervures distillent un lait empoisonné. Et, à un moment, comme Louise et Maxime riaient plus haut, dans le reflet jaune, dans le coucher de soleil du petit salon, Renée, l'esprit perdu, la bouche sèche et irritée, prit entre ses lèvres un rameau de Tanghin, qui lui venait à la hauteur des dents, et mordit une des feuilles amères (La Curée: 76).

La tanguina de Madagascar es el árbol prohibido de este jardín, cuyo fruto prueba Renée, y bajo el cual solía acostarse con Maxime: “D'habitude, les amants se couchaient sous le Tanghin de Madagascar, sous cet arbuste empoisonné dont la jeune femme avait mordu une feuille" (La Curée: 203).

Si consultamos las notas preparatorias de Zola para La Curée, encontramos que en la larga lista de especies vegetales que el autor constituyó para las descripciones del invernadero, aparece mencionado el "mancenillier" o manzanilla de la muerte. Esta planta, como todas las de la familia de las euforbiáceas, es poderosamente tóxica, resultando mortal para los seres humanos. Consideramos revelador el hecho de que Zola se plantease incluir esta planta en la descripción del invernadero, por varias razones: su fruto (aunque resulta mortal) es similar a la manzana, lo que recuerda a la del árbol prohibido del Edén bíblico. Es posible que Zola pensase en ella en este sentido para que fuese mordida por Renée, pero, de ser así, hubo de descartarla porque su ingesta hubiera sido letal para la mujer, y tuvo que limitarse a la consabida mención de la mordedura de la hoja de tanguina. Por otro lado, debido a su toxicidad, la manzanilla de la muerte resulta metafórica del contexto de depravación, de codicia y de vicio a ultranza en el que se desarrolla el relato. Además, es sabido que el contacto con la savia de esta planta produce una violenta sensación de ardor, inflamando los tejidos y ocasionando ampollas y erupciones en la epidermis, lo que viene a reforzar la presencia del elemento ígneo en el invernadero. En otro párrafo de las notas preparatorias, Zola ya escribe que "l'inceste [est] produit par cette terre de feu".

A pesar de que todos identificamos la manzana con la idea de pecado, lo cierto es que la Biblia no la menciona en absoluto: "Y como viese la mujer que el árbol era bueno para comer, apetecible a la vista y excelente para lograr sabiduría, tomó de su fruto y comió, y dio también a su marido, que igualmente comió" (Génesis, 3,6). Han sido las distintas confesiones religiosas las que han realizado su particular lectura sobre este pasaje, interpretándolo a su gusto. Así, para los católicos el fruto prohibido era una manzana, para los judíos era un higo, para los ortodoxos una naranja y, finalmente, para los musulmanes fue un vaso de vino. 
El motivo de la mordedura de la manzana nos remite también a un mito que trata sobre los amores incestuosos entre una madrastra y su hijastro: el de Fedra. Esta se enamoró tanto de Hipólito, que en su ansiedad perforaba todo el tiempo hojas del árbol del mirto.

Como indican Becker y Lavielle, para crear una nueva Fedra, y no una simple transposición del mito a la época contemporánea, Zola hace que en La Curée se consume el incesto. Quiere hacer hincapié en la decadencia de hábitos que caracteriza la sociedad del Segundo Imperio y en su ausencia de moralidad. No obstante, conserva ciertos aspectos del mito. La hoja de tanguina mordida por Renée celosa al ver a Maxime flirteando con Louise, recuerda al mirto de la leyenda (Becker \& Lavielle, opus cit.: 107-108).

Al comienzo de la novela, cuando asistimos al diálogo entre Renée y Maxime, durante su paseo en calesa, Renée da a entender que lleva una vida aburrida y carente de emociones, a lo que Maxime responde: 'Il n'y a pas de plaisir où tu n'aies mis les deux pieds, et si j'osais, si le respect que je te dois ne me retenait pas, je dirais... [...] Je dirais que tu as mordu à toutes les pommes" (La Curée: 44). Al final del capítulo I, Renée muerde la hoja de tanguina; a lo largo de los capítulos II y III, la acción se interrumpe para dar paso a un periodo de explicación-exposición. En el capítulo IV, esta acción se retoma donde había quedado interrumpida al final del capítulo I. Puesto que aquí Renée ya ha mordido la hoja de tanguina, ya se ha producido el punto de inflexión por el que ella está dispuesta a cometer el acto de depravación, y la sensación de calor que le ha dejado en los labios la mordedura de la hoja es una premonición de la sensación que experimentará al ser besada por Maxime: "La jeune femme avait, toute la nuit, gardé aux lèvres l'amertume du Tanghin; il lui semblait, à sentir cette cuisson de la feuille maudite, qu'une bouche de flamme se posait sur la sienne, lui soufflait un amour dévorant" (La Curée: 157).

A raíz de este acontecimiento, si bien la caída no se ha producido todavía en el sentido físico, sí que lo ha hecho en el espiritual. La mordedura de la hoja ha tenido el valor de un gesto iniciático, algo ha cambiado para siempre en el alma de la mujer: "À cette heure, elle voulut le mal, le mal que personne ne commet, le mal qui allait emplir son existence vide et la mettre enfin dans cet enfer, dont elle avait toujors peur, comme au temps où elle était petite fille" (La Curée: 198).

\section{Conclusión}

El análisis pormenorizado de las dos descripciones del invernadero del palacete Saccard, permite constatar hasta qué punto la mitología se erige en uno de sus ejes fundamentales. La sacralidad de la naturaleza alcanza una dimensión tan grande en Zola, que involucrarse con ella supone necesariamente entrar en contacto con dimensiones trascendentes, con lo oculto, lo imaginario y lo maravilloso. Tal es su exaltación de la creación y de la vida.

Esta mitología confiere una calidad singular a las presentaciones del invernadero, debido a la incorporación por parte del autor de significados nuevos, tales como el simbolismo de la luna, en el que asuntos de muy diversa índole se aúnan para formar un todo -como los ya citados de la mujer, las aguas, la vegetación, la serpiente, la fecundidad y la muerte-. O bien la mitología bíblica, que nos ha permitido 
establecer relaciones significativas entre la imagen zoliana del París del Segundo Imperio y las menciones bíblicas a las ciudades de Sodoma y Gomorra; así como la particular visión del autor de ciertos motivos que se enmarcan en el mito del Génesis, como los de la serpiente, el árbol y la manzana.

La pervivencia de una mitología tan abundante en el subconsciente de un escritor como Zola, que se esforzó tanto por dotar al realismo de un mayor valor científico, no hace sino ratificarnos en la idea de que, a pesar de las apariencias, la ruptura entre el ensueño y la ciencia no se ha completado aún en este período del siglo XIX.

\section{Referencias bibliográficas}

Albouy, P. (1970) "Quelques gloses sur la notion de mythe littéraire", in Revue d'Histoire littéraire de la France, 70ème année, № 5-6, sept.-déc., pp. 1059-1063.

Anfray, C., (2005) "La Faute (originelle) de l'abbé Mouret. Approche mythocritique du roman", in Les Cahiers Naturalistes. $\mathrm{N}^{\mathrm{o}} 79$, pp. 45-58.

Anfray, C., (2010) Zola biblique: La Bible dans les Rougon-Macquart. Paris, Cerf.

Becker, C. y V. Lavielle, (1999) La Curée. Paris, Bréal.

Cóndor, M., (2013) “Jardines, paraísos en la tierra”, in Descubrir el Arte. № 174, agosto.

Eliade, M., (1964) Tratado de historia de las religiones. París, Ediciones Cristiandad.

Hye-Jeong, J., (1994) L'Imaginaire d'Émile Zola autour de Mythe du Paradis. Thèse de doctorat en Littérature Française, Soutenue à Grenoble.

Ingeborg, W., (1990) Zola et la peinture.

Mitterand, H., (2002) Zola et le naturalisme. Paris, Presses universitaires de France.

Monod, J.-C., (2008) "Le mythe, de la terreur à l'esthétisation. Remarques sur le travail du mythe selon Hans Blumenberg", in Parizet, S. (dir.) Mythe et littérature. Nîmes / Paris: Lucie Éditions, p. 165.

Moreau, P.-L., (1995) “Le Mythe du paradis perdu dans La Faute de l'abbé Mouret”, in Actes des Septièmes Journées Nationales de Littérature Française. Tucumán, pp. 180-195.

Prado Biezma, J., (1995) "Du mythe à l'archéologie mythique", in Thélème, Revista Complutense de Estudios Franceses, $\mathrm{N}^{\circ} 7$.

Rabaté, E., (1989) “La Curée de Zola: le sens de métaphores", in Littérature. № 75, pp, 112123.

Ripoll, R., (1981) Réalité et mythe chez Zola. Thèse de doctorat. Université de Lille III.

Sánchez Luque, María Custodia (2016). Los jardines "pintados" de Émile Zola, lugares de encuentro entre literatura y arte. Tesis de doctorado. Universidad Complutense de Madrid.

Shinoda, Ch., (2001) "Exúberance végétale chez Mirbeau et Zola", in Cahiers Octave Mirbeau. $\mathrm{N}^{\circ} 8$, pp. 58-73.

Van Buuren, M. \& A. Firet, (1997) "Splendeur et misère: le Paris du Second Empire vu par Émile Zola", in Paris, de l'image à la mémoire: représentations artistiques, littéraires, sociopolitiques. Ámsterdam / Atlanta, Rodopoi.

Veloso Santamaría, I., (2004) "Naturalismo y religión: Émile Zola", in Ilu, Revista de Ciencias de las Religiones. $\mathrm{N}^{\circ} 9$.

Zola, É., (1871) La Curée. Paris, GF Flammarion. Préface par Claude Duchet.

Zola, É., (1880) "De la description", in Le roman expérimental. Paris, G. Charpentier, pp. 227-233. 